\title{
Testicular Mixed Yolk Sac Tumor and Teratoma with Seminoma
}

National Cancer Institute

\section{Source}

National Cancer Institute. Testicular Mixed Yolk Sac Tumor and Teratoma with

Seminoma. NCI Thesaurus. Code $C 8003$.

A malignant germ cell tumor arising from the testis. It is characterized by a mixture of yolk sac, teratomatous, and seminomatous morphologic elements. Patients may present with painless or painful testicular swelling. 